\title{
An electron microscopy study of the crystal growth of schwertmannite needles through oriented aggregation of goethite nanocrystals
}

\author{
James G. Hockridge, Franca Jones, Mitch Loan ${ }^{\mathrm{a}}$ and William R. Richmond* \\ Nanochemistry Research Institute, Curtin University of Technology, GPO Box U 1987, \\ Perth, 6845, Australia. Tel. +61 89266 3838, Fax. +61 892664699 \\ a Alcoa World Alumina - Australia, PO Box 161, Kwinana, 6167, Australia. \\ * Corresponding author. E-mail : w.richmond@curtin.edu.au
}

\begin{abstract}
The formation of the iron oxyhydroxide schwertmannite has been monitored by timeresolved TEM studies. Schwertmannite aggregates are found to form initially as spherical agglomerates of ferrihydrite crystallites, which then begin to grow characteristic needles on their surfaces. High resolution images of the needles show that they are initially comprised of aligned goethite nanocrystals, which subsequently coarsen to form crystallographically coherent needles of goethite. Thus, needle formation on schwertmannite aggregates can be considered as the first stage in the phase transformation from schwertmannite to goethite. The results of this study suggest that schwertmannite is not a distinct mineral phase, but may be mixture of ferrihydrite and poorly-crystalline goethite with a distinctive morphology directed by the presence of surface-adsorbed sulfate anions.
\end{abstract}

KEYWORDS: (B1) Iron oxides, crystal morphology, characterisation, (A1) oriented aggregation. 


\subsection{INTRODUCTION}

Schwertmannite is a poorly-crystalline iron oxyhydroxide that forms specifically in acidic sulfate media, and is known to occur as an environmental precipitate in acid mine drainage sites.[1] Schwertmannite has also been found to precipitate as a component of hydrometallurgical streams containing precipitated iron, [2, 3] and thus its structure, its composition, the conditions required for its formation, and the mechanism by which its unique morphology develops, have been a subject of considerable interest to researchers seeking to understand the complex chemistry of iron oxyhydroxide precipitation.[4, 5]

Schwertmannite can be identified readily by its characteristic "hedge-hog" morphology: samples are typically composed of rounded aggregates a few hundred nanometers in diameter, made up of fine radiating whiskers, or needles 2-10 nanometers in width. Schwertmannite was first described by Bigham et al.[6, 7] and its structure has been described as being very similar to $\beta-\mathrm{FeOOH}$, with sulfate anions incorporated into tunnel sites within the iron oxyhydroxide lattice.

Schwertmannite is stable with respect to ferrihydrite in acidic, sulfate-rich suspensions, but metastable with respect to goethite. The transformation of ferrihydrite to goethite has been shown to occur via a dissolution/reprecipitation mechanism where goethite crystals form in solution from dissolved Fe(III) ions in equilibrium with ferrihydrite.[8, 9] More recent work has demonstrated that goethite nanorods can form by an oriented aggregation mechanism in which ferrihydrite nanoparticles transform to goethite nanoparticles, which then assemble into rods through some form of recognition

aggregation.[9, 10] Subsequent aging of the oriented aggregates gives rise to coherent crystalline nanorods of goethite. Various crystal morphologies have been described for goethite, but goethites formed in acidic sulfate solutions have usually been reported to be nanocrystalline in nature, with rod-like morphology, and often forming larger aggregates of aligned rods or laths.[11-14]

In a recent publication, it was reported that samples of ferric oxyhydroxide grown in the presence of arsenate often contain aggregates that, when viewed at low magnification in the transmission electron microscope, closely resemble the hedge-hog morphology characteristic of schwertmannite.[15, 16] Powder XRD patterns of these materials were suggestive of 2-line ferrihydrite, and higher magnification TEM images revealed that the aggregates were indeed made up of ferrihydrite crystallites, with peripheral ferrihydrite nanoparticles arranged to form 'whiskers' similar to those seen in 
schertmannite.[16] These observations seemed to indicate however, that schwertmannite may form via a mechanism involving aggregation of ferrihydrite crystallites.

The use of electron nanodiffraction in a Scanning Transmission Electron Microscope (STEM nanodiffraction) has also been reported, and diffraction patterns on individual schwertmannite needles have been analysed in an attempt to characterise the structure of schwertmannite.[17] The results of this study suggested that schwertmannite contained subunits with spinel-type symmetry, a structural component that has also been observed in nanodiffraction experiments on 2-line ferrihydrite. This study didn't draw firm conclusions about the schwertmannite structure, other than to note a strong similarity to the results obtained from 2-line ferrihydrite, and to suggest that there was no evidence for the presence of an akaganéite-like structure. Subsequent work investigating electronbeam induced changes to iron oxyhydroxides has raised concerns about the stability of schwertmannite needles under the focussed electron beam of the STEM, and thus the results of nanodiffraction experiments are open to dispute[18] and thus significant question remain about the structure of schwertmannite and the mechanism by which its morphology develops.

In this paper we describe an investigation of schwertmannite growth by using high-resolution TEM images to examine the development of needles at selected time intervals in the growth process. The results provide important insights into the mechanism by which the characteristic radiating needles form. They also provide evidence suggesting that schwertmannite is not a distinct oxyhydroxide phase with a unique structure, but is instead composed of ordered assemblies of goethite and ferrihydrite nanocrystals.

\subsection{EXPERIMENTAL PROCEDURE}

$0.4 \mathrm{~g}$ of ferric sulfate $\left(\mathrm{Fe}_{2}\left(\mathrm{SO}_{4}\right)_{3} \cdot \mathrm{xH}_{2} \mathrm{O}\right)$ was added to $250 \mathrm{ml}$ of Milli-Q water in a polypropylene bottle at ambient temperature, and the bottle was immediately sealed and placed in a bottle roller thermostatted at $85{ }^{\circ} \mathrm{C}$. Samples were taken at intervals of 2, 5, 10, 15, 30 and 60 minutes and the suspensions cast directly onto a conventional copper TEM grid and allowed to dry in air.

Samples for powder X-ray diffraction analysis were prepared in a separate experiment in which a number of $250 \mathrm{ml}$ bottles containing ferric sulfate solution $(1 \mathrm{~g} / \mathrm{L})$ 
were placed in the bottle roller at $85^{\circ} \mathrm{C}$, and removed after selected time intervals of up to 24 hours. As each bottle was removed from the bottle roller, the sample was rapidly filtered under reduced pressure and the solid cooled and freeze-dried.

$\mathrm{X}$-ray powder diffraction was carried out at $298 \mathrm{~K}$ using $\mathrm{Cu}-\mathrm{K} \alpha$ radiation $(40 \mathrm{kV}$, $30 \mathrm{~mA}$ ) on a Seimens D500 diffractometer. The samples were step scanned from $3^{\circ}$ to $70^{\circ} 2 \Theta$, at $0.02^{\circ}$ increments, using a counting time of $5 \mathrm{~s}$ per increment.

In turbidity experiments, a $0.7 \mathrm{~g} / \mathrm{L}$ solution of ferric sulfate was prepared at room temperature, and then placed into a water bath at $85^{\circ} \mathrm{C}$. Using a UV-Visible spectrometer, turbidity was monitored over a period of 400 minutes by measuring the absorbance at 900 $\mathrm{nm}$. Since the iron and/or sulfate are not expected to have any appreciable absorbance at $900 \mathrm{~nm}$, the absorbance can be related to the turbidity; the turbidity is the light scattered by the particles in suspension, and provided the scattered light does not reach the detector, it can be measured as a transmittance or absorbance value. A sample was taken at a given time, placed into a quartz cuvette, covered with a lid and prior to measurement was gently shaken to suspend all the particles. The absorbance reading was taken three times and the average calculated. The reaction was sampled at regular intervals and the sub-samples were filtered and the sulfate concentration determined by ICP-AES analysis.

Transmission Electron Micrographs were recorded on a JEOL 2011 TEM operating at $200 \mathrm{kV}$, or on a JEOL 3000 FEG TEM operating at $300 \mathrm{kV}$. All highresolution (HRTEM) images were collected on the JEOL 3000. The sensitivity of the samples to damage by the electron beam presented challenges in obtaining highresolution images. In order to minimize exposure of the sample to the electron beam, initial alignment and focusing at high magnification was carried out on one region of the sample, and then the sample was moved to a new region of interest and digital images collected rapidly. Multiple images collected in this manner along with the investigation of the effects of deliberate degradation of the needles in the beam, enable us to be confident that we have obtained images of unaltered schwertmannite needles.

\subsection{RESULTS}

\subsection{Time-Resolved TEM}

When heating ferric sulfate solutions at $85{ }^{\circ} \mathrm{C}$, formation of a visible precipitate was evident after 5-10 minutes, and colloidal suspensions formed at this time tended to 
settle after about 1 hour. Samples taken after longer times tended to settle more rapidly and were present in higher yield than the initial colloidal products. Powder XRD analysis of these samples gave patterns characteristic of schwermannite in products collected after 15 minutes or longer.

The development of schwertmannite aggregates was tracked by TEM examination of samples taken at different time intervals, as shown by the images presented in Figure 1. The initial precipitate in the hydrolysis reaction, sampled after 5 minutes, forms compact globular aggregates of $>100 \mathrm{~nm}$ diameter, as shown in Figure 1a. At low magnification, this material appears to be amorphous. The appearance of the characteristic schwertmanite needles is rapid, and after 10 minutes, we can see short needles radiating from the surface of the spherical aggregates. The typical schwertmannite morphology is well developed after 1 hour (Figure 1c) with radiating whiskery needles many tens of nanometers in length completely surrounding the aggregates.

These images provide some important information as to the mechanism of growth of schwertmannite aggregates. It is now clear that the needles do not grow out from a small central nucleus, but instead form and grow on the surface of large spherical aggregates. The study of schwertmannite by electron microscopy is hindered by the fact that the aggregates are large and too dense to be transparent to the electron beam, so electron microscopy cannot reveal whether the material at the centre of schwertmannite aggregates is crystalline in nature. We cannot be sure whether the cores of the schwertmannite aggregates also change in some way as the reaction progresses and needles grow out from their surface.

Further images of schwertmannite samples are presented in Figure 2, showing the development of the whiskers on the surface of the central aggregates. The average length of the whiskers can be estimated from such images to give some idea as to how they develop over time. The dense central core of the schwertmannite aggregates makes it difficult to accurately measure the length of the needles, but it can be seen that after 10 minutes the needles are generally $<50 \mathrm{~nm}$ in length, while at 15 minutes, the needles are approximately $100 \mathrm{~nm}$ long, and have extended to $100-200 \mathrm{~nm}$ in length after 60 minutes. 
TEM examination of products aged for 60 minutes showed two different types of aggregates within the sample. In addition to the normal schwertmannite structures, many of the aggregates had shorter, straight needles and appeared less spherical than the common schwertmannite balls. Figure 2(d) shows a typical aggregate observed in the 60 minute sample that contains both morphologies. The elliptical aggregates to the right of this image have a morphology consistent with nanocrystalline goethite, and selected area electron diffraction of these aggregates provided evidence of greater degree of crystallinity than that observed for typical schwertmannite aggregates.

\subsection{Powder X-Ray diffraction and turbidity measurements}

Figure 3 shows the powder XRD patterns obtained for precipitates collected at selected time intervals up to 2 hours during hydrolysis of ferric sulfate solutions at $85{ }^{\circ} \mathrm{C}$. Samples taken at 15 mins and 30 mins showed patterns typical of schwertmannite, but after 2 hours reaction time the XRD patterns indicated the appearance of some poorlycrystalline goethite, and the relevant peaks in the pattern can be identified in Figure 3 by comparison with the major lines in the goethite powder diffraction file (JCPDS 29-0713). XRD patterns do not show any indication of goethite reflections in the samples collected at 15 and 30 minutes however, which suggests that if any goethite is present after these reaction times, it is present in too small an amount and/or present as very small crystallites such that it cannot be detected in the powder XRD pattern of the bulk material.

Linewidth analysis based on the (101) reflection in the 2 hour sample indicated a crystallite size of $\sim 10 \mathrm{~nm}$. Additional powder XRD patterns for samples collected at intervals from 2 hours to 24 hours showed only a minor increase in crystallite size over the 24-hour period covered by the data, with an approximate size of $\sim 12 \mathrm{~nm}$ being determined for samples collected from 5 to 24 hours.

The progress of crystallisation has also been monitored with a combination of turbidity measurements and sulfate concentration measurements over a 3-hour period. Curves showing turbidity and sulfate concentration changes over this time scale are presented in Figure 4. The curves reveal that both turbidity and sulfate concentration do not stabilize until after $\sim 60$ minutes of the reaction. After this time, there is a gradual decrease in turbidity which we attribute to phase transformation of schwertmannite to 
goethite. XRD patterns indicate an increase in the intensity of goethite peaks during this period of time, and the drop in turbidity suggests that this process occurs via a dissolution/re-precipitation mechanism.

The absence of any change in the sulfate concentration during this time however, suggests that the phase transformation to goethite may be far from complete within the timeframe of this experiment. Bigham et al.[19] demonstrated that schwertmannite, on conversion to goethite, releases sulfate ions and $\mathrm{H}^{+}$, although the timeframe of this transformation was a period of years with the suspension held at room temperature, so it perhaps not surprising that our own results do not show a similar release of sulfate ions. XRD patterns measured for samples treated for up to 24 hours did show increased intensities of the goethite peaks, but it was clear that only a small portion of the schwertmannite sample had transformed to goethite, since a background of broad peaks was still evident in the pattern obtained after 24 hours.

\subsection{High-Resolution TEM}

High resolution TEM can provide some further information about the structural nature and mechanism of formation of the schwertmannite needles. Figure 4 shows a typical high resolution image of one of the aggregates observed after 5 minutes reaction time. Visible lattice fringes indicate that the aggregate is comprised of crystallites of approximately 5-7 nm diameter. Lattice spacings measured for these crystallites in numerous aggregates varied between $2.43 \AA$ and $2.47 \AA$, with an average spacing of 2.45A, which is a close match to the spacing of $\{011\}$ planes in ferrihydrite.[20] These aggregates observed in the earliest phase of schwertmannite formation did not show any sign of the needles or whiskers typical of the schwertmannite morphology and on the basis of our TEM observations we conclude that the initial precipitate in this reaction is best described as dense spherical aggregates of ferrihydrite nanocrystals.

To examine the mechanism of needle formation more closely, highresolution images of nascent needles from samples taken after 15 minutes reaction time are shown in Figure 6. In these images we can see that the needles taper slightly, and are not straight-edged, but rather appear to be composed of individual crystalline particles about $5 \mathrm{~nm}$ in diameter. Lattice fringes on the schwertmannite needles shown in Figure 6 indicate that the needles are composed of goethite nanocrystals; the fringes labelled in the 
image on the left gave a $d$-spacing of approximately $0.4 \mathrm{~nm}$, corresponding to the (101) spacing in goethite. The ends of the needles shown in Figure 6 display a "kink" that is characteristic of schwertmannite needles we have observed in many samples, and the arrangement of the primary particles is indicative of oriented aggregation of goethite nanocrystals twinned along the (210) plane.[21]

Oriented aggregation is a form of particle aggregation in which primary crystallites combine reversibly to form an aggregate on the basis of various possible interparticle interactions.[22] The primary crystallities may then re-orient themselves with respect to one another through Brownian motion, leading to aggregates with an energetically favourable structural alignment of the subunits. Oriented aggregation mechanisms have been described in a number of recent articles concerned with nanoparticle formation and aggregation,[9, 22-28] and some of these have demonstrated the role of oriented aggregation in the transformation of ferrihydrite to other iron oxyhydroxides.[9, 23, 24, 26]

HRTEM examination of schwertmannite needles after a reaction time of 60 minutes shows that many of the needles have a much more coherent orientation of lattice fringes than those presented in Figure 6. The schwertmannite needle shown in Figure $7 \mathrm{~b}$ is an example, in which lattice fringes reveal that all sections of the needle are crystallographically aligned. The fourier transform of a section of the image (Figure 7c) shows the pattern characteristic of an orientation close to the [111] zone axis of goethite, confirming that this schwertmannite needle is composed of crystallographically aligned goethite subunits. Measurement of spacings from lattice fringes on this image provided further confirmation that the needle has a goethite structure: $4.25 \AA$ and $2.53 \AA$ for (101) and (011) planes respectively, as indexed on the simulated diffraction pattern shown in Figure 7(d). These results match closely with the expected d-spacings of $4.190 \AA$ for the (101) planes and $2.522 \AA$ for the (011) planes in goethite.

\subsection{DISCUSSION}

Both the structure of schwertmannite, and the mechanism by which its distinctive hedge-hog morphology develops have been the subject of conjecture for some time,[15, 16] but the images presented here provide clues that may help answer both of these 
questions. TEM images of samples collected after only 5 minutes reaction time show that the iron oxyhydroxide phase that precipitates initially is ferrihydrite. The aggregates are dense, roughly-spherical and appear to be composed of randomly-oriented ferrihydrite crystallites. We were unable to isolate sufficient sample for XRD analysis of the product at this early stage of the reaction, but the crystallinity and size of the nanocrystals making up these aggregates would lead us to expect that it is more likely to be 6-line rather than 2-line ferrihydrite.

The emergence of a morphology that can be considered characteristic of schwertmannite (i.e. the formation of radiating needles) is first evident in the samples taken after 15 minutes. The images presented in Figure 6 show that the needles are composed of goethite nanocrystals that appear to align via an oriented aggregation process. Previous studies have shown that when goethite crystallises by this mechanism, goethite nanocrystals form at the expense of the ferrihydrite precursor particles, then aggregate in oriented alignment to form nanorods.[9, 10] The nanorods can then undergo a change to a more regular morphology through a process of slow recrystallisation and coarsening to produce particles that display crystallographic order over a much larger scale.[9] The images presented in Figures 6 and 7 suggest that a similar mechanism could account for the formation of schwertmannite needles, and the subsequent emergence of goethite "rafts". Aggregates formed in the early stages of the reaction contained nanoscale crystallites with lattice fringes matching ferrihydrite, and no individual particles with goethite lattice spacings were observed in these samples. Once needle formation had commenced on the periphery of aggregates, we observed only goethite lattice spacings in the crystallites that made up the needles. By this stage of the growth process, it was not possible to observe lattice fringes of particles located in the heart of the aggregates, but on the basis of our powder XRD data, we propose that bulk samples must still contain a large proportion of ferrihydrite even after the typical schwertmannite morphology has been established. Thus we conclude that the schwertmannite aggregates contain a central core of ferrihydrite surrounded by radiating needles composed of goethite nanocrystals.

The formation of schwertmannite needles by oriented aggregation may also explain the surprising kinks and twists in the needles that are often observed. The images presented in Figure 6 reveal how 'bent' needles can form by oriented alignment of goethite nanocrystals along a (210) twin plane, resulting in a $117.5^{\circ}$ bend in the needle 
axis. Further "twinned" alignment can then allow the needles to form the more convoluted spirals that are sometimes observed.

In order to consider the effects of adding nanocrystalline goethite on the powder XRD patterns of ferrihydrite, some rudimentary pattern prediction was carried out using the Crystal Diffract[29] software package. Some predicted patterns are shown in Figure 8 and compared to the experimental pattern observed for the schwertmannite sample collected after 15 minutes reaction time. Selection of a model structure for ferrihydrite was problematic in this exercise, given that the structure of ferrihydrite is still the subject of some debate.[30, 31] The ferrihydrite structural model we have used to generate these simulated patterns was that proposed by Jansen et al.[20] and the overall model is based on mixtures of $6 \mathrm{~nm}$ ferrihydrite nanocrystals and $3 \mathrm{~nm}$ goethite nanocrystals. While these models are somewhat speculative, the simulated patterns provide some indication that our interpretation of the growth process is reasonable at least in regard to the fact that small amounts of nanocrystalline goethite may not be evident in the XRD patterns of the bulk material..

We estimate, on the basis of the simulated diffraction patterns for mixtures of nanocyrstalline goethite and ferrihydrite, that major reflections due to goethite would not be evident in the mixture until the amount of goethite present exceeds about $10 \%$. Time resolved powder XRD patterns of schwertmannite samples do not show any clear indication of the presence of goethite until at least 60 minutes reaction time, although TEM images show that needle development begins much earlier, and that discrete nanoparticles within the needles appear to have a goethite structure. So it seems likely that in the first 60 minutes of schwertmannite formation, the only goethite crystallites present are those that form the outer layer of the aggregates (the radiating needles), while the internal bulk of the aggregates during this time remains composed of ferrihydrite. As the reaction progresses further, the metastable ferrihydrite phase will gradually disappear and the needles will grow longer. After 60-120 minutes reaction time, the schwertmannite needles no longer show evidence of being composed of aggregates of goethite nanocrystals; they show coherent lattice fringes along their whole length. At this stage in the reaction, the goethite crystallites appear to be of sufficient size and order to begin to show indication of goethite peaks in the XRD pattern of the bulk material, as demonstrated in the XRD pattern shown in Figure 3. 
The goethite needles that radiate from schwertmannite aggregates are not however, of the same morphology as the goethite aggregates observed when the reaction is allowed to progress for much longer times, and indeed it is well know that schwertmannite is itself a metastable oxyhydroxide, and that goethite laths will form in systems aged over a period of days or weeks at room temperature. It has been reported that this transformation results in the release of sulfate ions from the solid[19], and this observation has been taken as evidence that sulfate was structurally incorporated within the schwertmannite lattice.

In our experiments, we have found no evidence of any lattice fringes in schwertmannite needles that could be attributed to an akaganeite-like phase, and we have not observed any re-release of sulfate into the solution as the initial ferrihydrite phase transforms to goethite. However, as the total yield of schwertmannite in the suspension we have studied is quite low ( $<\sim 1 \mathrm{~g}$ in $250 \mathrm{ml}$ ) it is possible that over the timeframe of our experiments, the small amounts of goethite formed are insufficient to lead to a measurable change in free sulfate concentration. A further possible explanation for this is that the sulfate content of schwertmannite aggregates may be due to surface adsorption, [32]given that the schwertmannite morphology provides very high surface area. The release of sulfate observed by Bigham et al.[19] as the schwertmannite phase transformed to goethite, may simply be due to the corresponding decrease in surface area that would be inherent in such a transformation.

We note that the formation of radiating goethite needles on a central iron oxide aggregate has been described previously in two interesting and relevant publications.[11, 33] In these examples, goethite needles were found to form on the surface of larger $\mathrm{Fe}_{2} \mathrm{O}_{3}$ particles when suspensions of these particles contained sulfate ions. Previous studies describing the oriented aggregation of goethite nanocrystals have monitored the transformation of ferrihdyrite to goethite in ferric nitrate solutions, [9, 10] or in iron solutions selected as biomimetic models,[24] but oriented aggregation in ferric sulfate media has not been previously described. However, the evidence provided here suggests that the basic mechanism of goethite formation in schwertmannite needles is essentially the same as described in other media, so it seems that oriented aggregation and subsequent coarsening of nanoparticles may be a generally applicable mechanism for goethite growth in acidic conditions. The morphology of the "coarsened" goethite assemblies appears more variable however, and in the case of schwertmannite, the 
characteristic balls of radiating needles may arise as the result of specific surface interactions between the goethite nanocrystals and the sulfate anion.

\section{ACKNOWLEDGEMENTS}

This work was supported under the Australian Research Council's Discovery Grant Scheme, grant number DP0451535. Some of the electron microscopy described here was carried out using facilities at the Centre for Microscopy, Characterisation and Analysis, The University of Western Australia, which are supported by University, State and Federal Government funding. The assistance of Dr Martin Saunders is also gratefully acknowledged. 


\section{REFERENCES}

[1]. Bigham, J. M.; Nordstrom, D. K., Iron and Aluminium Hydroxysulfates from Acid Sulfate Waters. In Sulfate Minerals - Crystallography, Geochemistry and Environmental Significance, Alpers, C. N.; Jambor, J. L.; Nordstrom, D. K., Eds. Mineralogical Society of America: Washington D.C., 2000; Vol. 40, pp 351-403.

[2]. Claassen, J. O.; Meyer, E. H. O.; Rennie, J.; Sandenbergh, R. F., Iron precipitation from zinc-rich solutions: defining the Zincor Process. Hydrometallurgy 2002, 67, (1-3), 87-108.

[3]. Zinck, J. M.; Dutrizac, J. E., The Behaviour of Zinc, Cadmium, Thallium, Tin and Selenium during Ferrihydrite Precipitation from Sulphate Media. CIM Bulletin 1998, 91, (1019), 94-100.

[4]. Barham, R. J., Schwertmannite : A unique mineral, contains a replaceable ligand, transforms to jarosites, hematites, and/or basic iron sulfate. Journal of Materials Research 1997, 12, (10), 2751-2758.

[5]. Mazzetti, L.; Thistlethwaite, P. J., Raman spectra and thermal transformations of ferrihydrite and schwertmannite. Journal of Raman Spectroscopy 2002, 33, (2), 104-111.

[6]. Bigham, J. M.; Schwertmann, U.; Carlson, L.; Murad, E., A poorly crystallixed oxy-hydroxysulfate of iron formed by bacterial oxidation of $\mathrm{Fe}(\mathrm{II})$ in acid mine waters. Geochimica et Cosmochimica Acta 1990, 54, 2743-2758.

[7]. Bigham, J. M.; Carlson, L.; Murad, E., Schwertmannite, a new iron oxyhydroxy sulfate from Pyhäsalmi, Finland, and other localities. Mineralogical Magazine 1994, 58, 641-648.

[8]. Schwertmann, U.; Murad, E., Effect of $\mathrm{pH}$ on the formation of goethite and hematite from ferrihydrite. Clays \& Clay Minerals 1983, 31, (4), 277-184.

[9]. Burleson, D. J.; Penn, R. L., Two-step growth of goethite from ferrihydrite. Langmuir 2006, 22, 402-409.

[10]. Penn, R. L.; Erbs, J. J.; Guliver, D. M., Controlled growth of alpha-FeOOH nanorods by exploiting oriented aggregation. Journal of Crystal Growth 2006, 293, 1-4.

[11]. Sugimoto, T.; Wang, Y., Mechanism of the Shape and Structure Control of Monodispersed $\alpha-\mathrm{Fe}_{2} \mathrm{O}_{3}$ Particles by Sulfate Ions. Journal of Colloid and Interface Science 1998, 207, 137-149.

[12]. Loan, M.; Newman, O. G. M.; Farrow, J. B.; Parkinson, G. M., Continuous reactive crystallization of nanoscale 6-line ferrihydrite. Crystal Growth and Design 2006, 6, (1), 79-86. 
[13]. Parida, K. M.; Das, J., Studies on ferric oxide hydroxides (II) Structural properties of goethite samples $(\alpha-\mathrm{FeOOH})$ prepared by homogeneous precipitation from $\mathrm{Fe}\left(\mathrm{NO}_{3}\right)_{3}$ solution in the presence of sulfate ions. Journal of Colloid \& Interface Science 1996, 178, 586-593.

[14]. Music, S.; Krehula, S.; Popovic, S.; Skoko, Z., Some factors influencing forced hydrolysis of $\mathrm{FeCl}_{3}$ solutions. Materials Letters 2003, 57, (5-6), 1096-1102.

[15]. Richmond, W. R.; Loan, M.; Morton, J.; Parkinson, G. M., Arsenic removal from aqueous solution via ferrihydrite crystallization control. Environmental Science and Technology 2004, 38, (8), 2368-2372.

[16]. Loan, M.; Richmond, W. R.; Parkinson, G. M., On the Crystal Growth of Nanoscale Schwertamannite. Journal of Crystal Growth 2005, 275, e1875-e1881.

[17]. Loan, M.; Hart, R. D.; Cowley, J. M.; Parkinson, G. M., Evidence on the structure of synthetic schwertmannite. American Mineralogist 2004, 89, 1735-1742.

[18]. Pan, Y.; Brown, A.; Brydson, R.; Warley, A.; Li, A.; Powell, J., Electron beam damage studies of synthetic 6-line ferrihydrite and ferritin molecule cores within a human liver biopsy. Micron 2006, 37, 403-411.

[19]. Bigham, J. M.; Schwertmann, U.; Traina, S. J.; Winland, R. L.; Wolf, M., Schwertmannite and the chemical modeling of iron in acid sulfate waters. Geochimica et Cosmochimica Acta 1996, 60, (12), 2111-2121.

[20]. Jansen, E.; Kyek, A.; Schäfer, W.; Schwertmann, U., The structure of 6-line ferrihydrite. Applied Physics A : Material Science and Processing 2002, 74, (Supplement 1), S1004-S1006.

[21]. Cornell, R. M.; Schwertmann, U., The Iron Oxides. 2nd Edn. ed.; VCH: Weinheim, 2003.

[22]. Penn, R. L., Kinetics of oriented aggregation. Journal of Physical Chemistry B 2004, 108, 12707-12712.

[23]. Banfield, J. F.; Welch, S.; Zhang, H.; Ebert, T. T.; Penn, R. L., Aggregation-based Crystal Growth and Microstructure Development in Natural Iron Oxyhydroxide Biomineralization Products. Science 2000, 289, 751-754.

[24]. Nesterova, M.; Moreau, J.; Banfield, J. F., Model biomimetic studies of templated growth and assembly of nanocrystalline FeOOH. Geochimica et Cosmochimica Acta 2003, 67, (6), 1177-1187.

[25]. Pacholski, C.; Kornowski, A.; Weller, H., Self-assembly of ZnO: From nanodots to nanorods. Angewandte Chemie-International Edition 2002, 41, (7), 1188-1191.

[26]. Guyodo, Y.; Mostrom, A.; Penn, R. L.; Banerjee, S. K., From nanodots to nanorods: Oriented aggregation and magnetic evolution of nanocrystalline goethite. Geophysical Research Letters 2003, 30, (10), 1512-1515. 
[27]. Huang, F.; Zhang, H.; Banfield, J. F., Two-stage crystal growth kinetics observed during hydrothermal coarsening of nanocrystalline ZnS. Nano Letters 2003, 3, (3), 373378.

[28]. Huang, F.; Zhang, H.; Banfield, J. F., The role of oriented attachment crystal growth in hydrothermal coarsening of nanocrystalline ZnS. Journal of Physical Chemistry B 2003, 107, 10470-10475.

[29]. Palmer, D. Crystal Diffract, 5.0.1; CrystalMaker Software Ltd.: Yarnton, UK, 2005.

[30]. Michel, F. M.; Ehm, L.; Antao, S. M.; Lee, P. L.; Chupas, P. J.; Liu, G.; Strongin, D. R.; Schoonen, M. A. A.; Phillips, B. L.; Parise, J. B., The structure of ferrihydrite, a nanocrystalline material. Science 2007, 316, 1726-1729.

[31]. Rancourt, D. G.; Meunier, J.-F., Constraints on structural models of ferrihydrite as a nanocrystalline material. American Mineralogist 2008, 93, 1412-1417.

[32]. Tanabe, K.; Hattori, H.; Yamaguchi, T.; Lizuka, T.; Matzuhashi, H., Fuel Processing Technology 1986, 14, 247.

[33]. Carbone, C.; Di Benedetto, F.; Marescotti, P.; Sangregorio, C.; Sorace, L.; Lima, N.; Romanelli, M.; Lucchetti, G.; Cipriani, C., Natural Fe-oxide and -oxyhydroxide nanoparticles: and EPR and SQUID investigation. Mineralogy and Petrology 2005, 85, 19-32. 

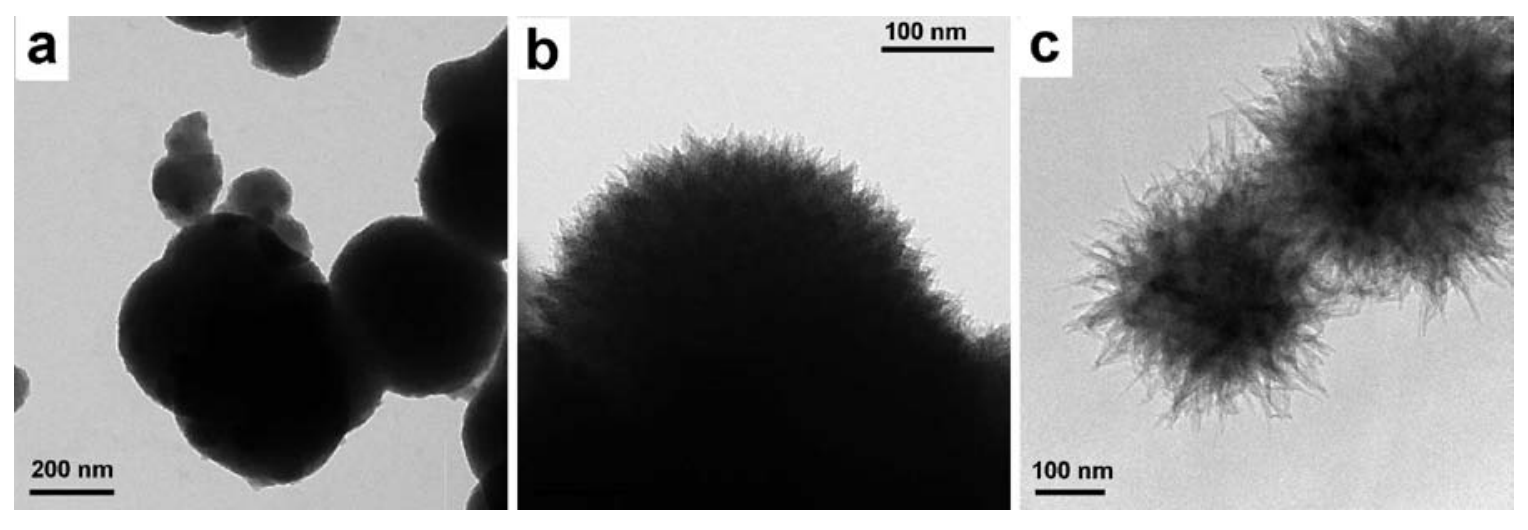

Figure 1: TEM images showing the time-resolved formation of schwertmannite aggregates from $0.7 \mathrm{~g} \mathrm{~L}^{-1} \mathrm{Fe}^{3+}$ (as ferric sulfate) solutions $\left(85^{\circ} \mathrm{C}\right.$ ), after (a) 5, (b) 10 and (c) 60 minutes. 

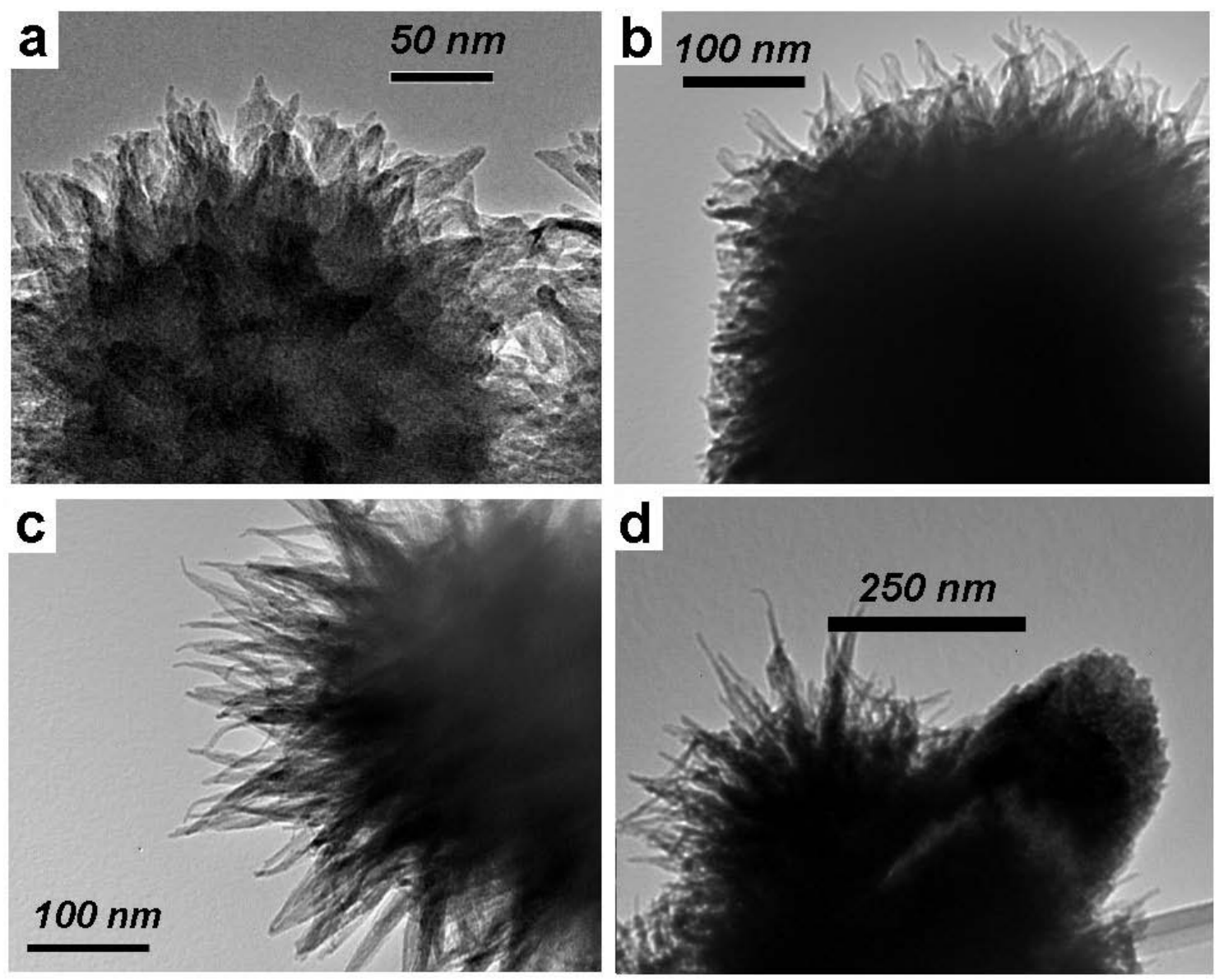

Figure 2: TEM images showing the development of schwertmannite needles at (a)10 minutes, (b) 15 minutes and (c) 30 minutes reaction time. Image (d) shows an agglomerate with a mixture of schwertmannite and goethite-like aggregates in a sample aged for 60 minutes. 


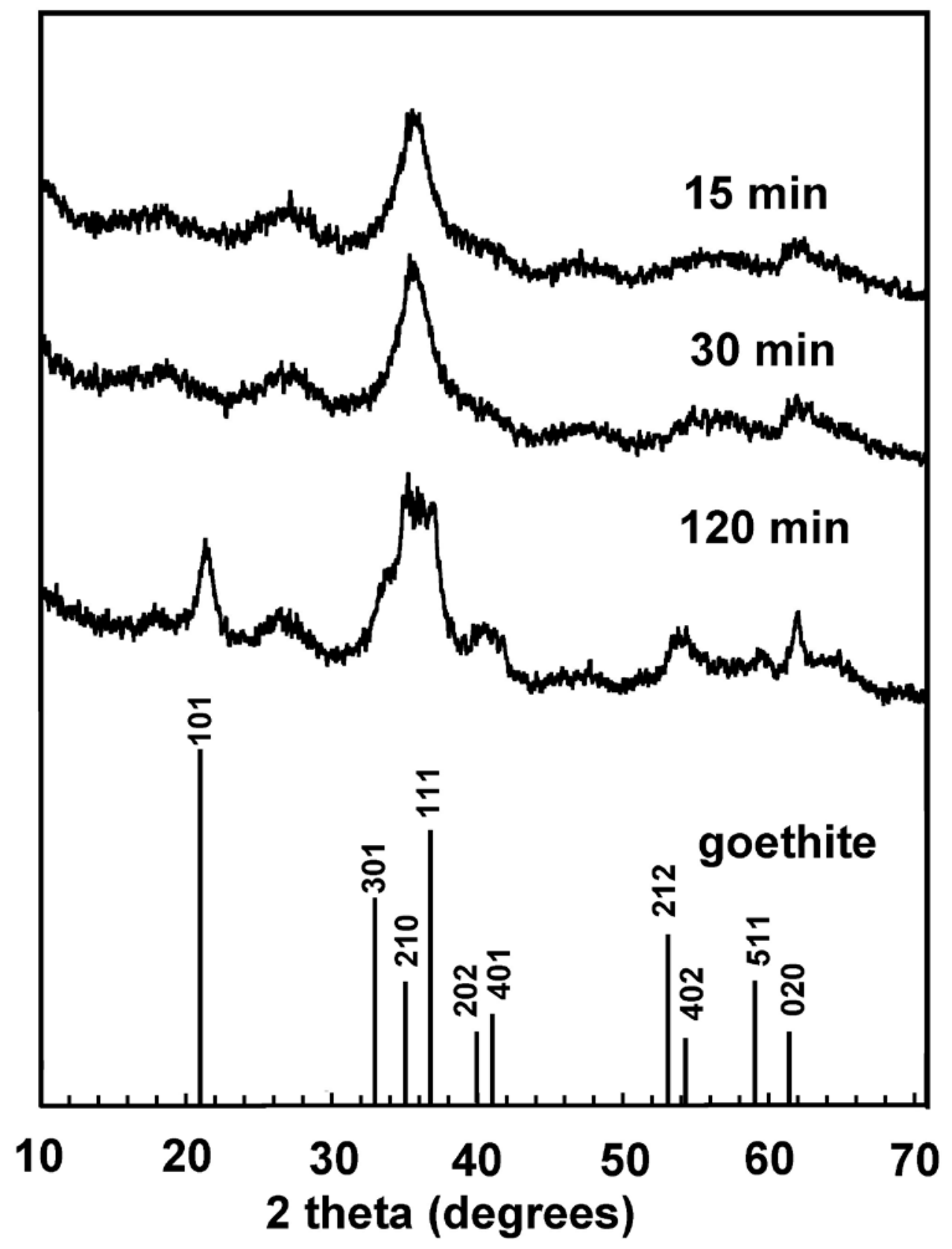

Figure 3 : Powder XRD patterns of products formed after 15, 30 and 120 minutes in the hydrolysis of ferric sulfate solution at $85^{\circ} \mathrm{C}$. The appearance of poorly crystalline goethite in the sample taken at 120 min can be seen by comparison with positions of the ten most intense goethite reflections shown at the bottom of the figure (JCPDS \# 290713). 


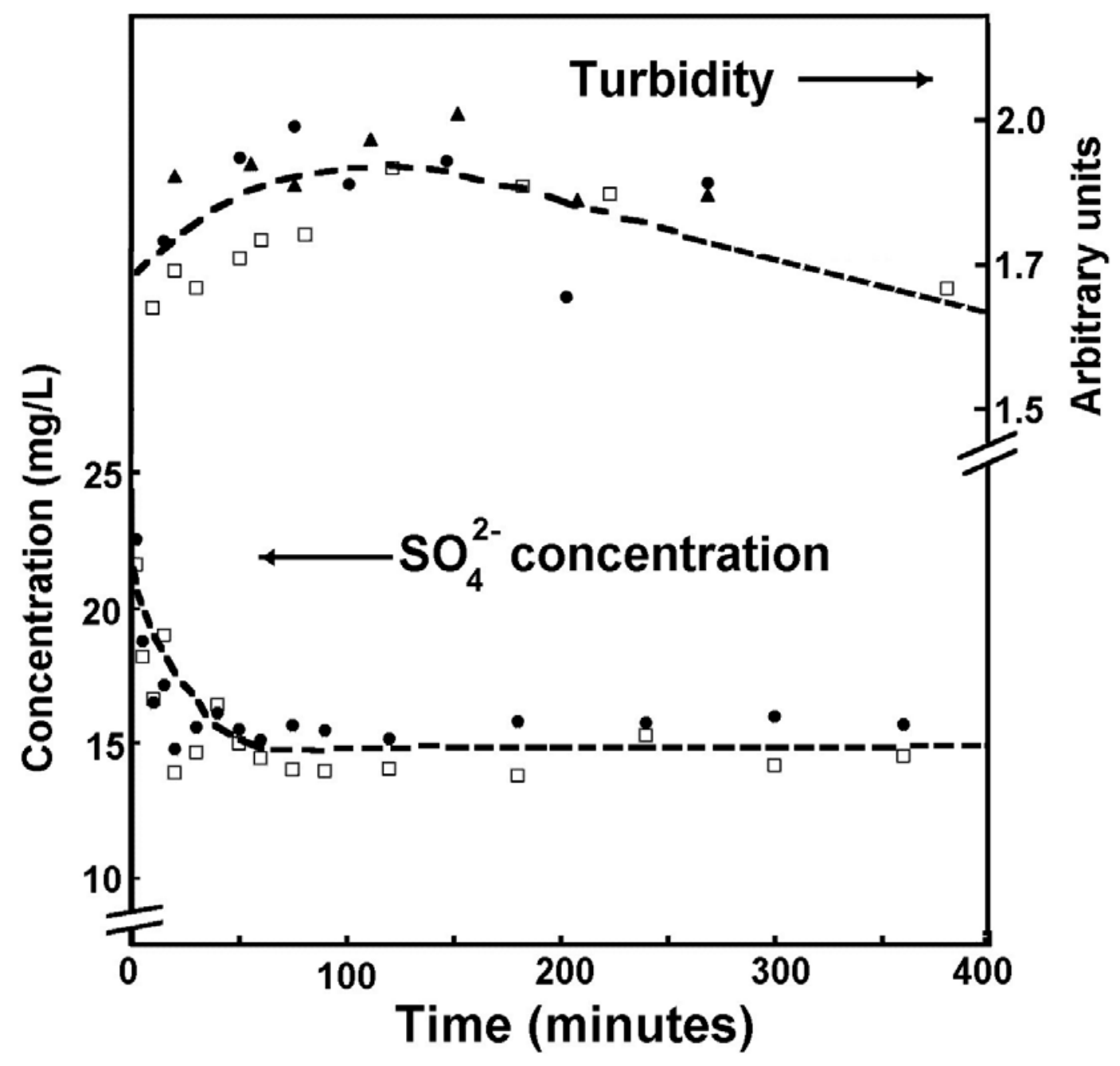

Figure 4: Changes in turbidity (top curve) and sulfate concentration (bottom curve) during hydrolysis of $0.7 \mathrm{~g} / \mathrm{l}$ ferric sulfate solutions at $85{ }^{\circ} \mathrm{C}$. The turbidity curve contains data from triplicate runs, and the sulfate concentration curve contains data from duplicate experiments. 


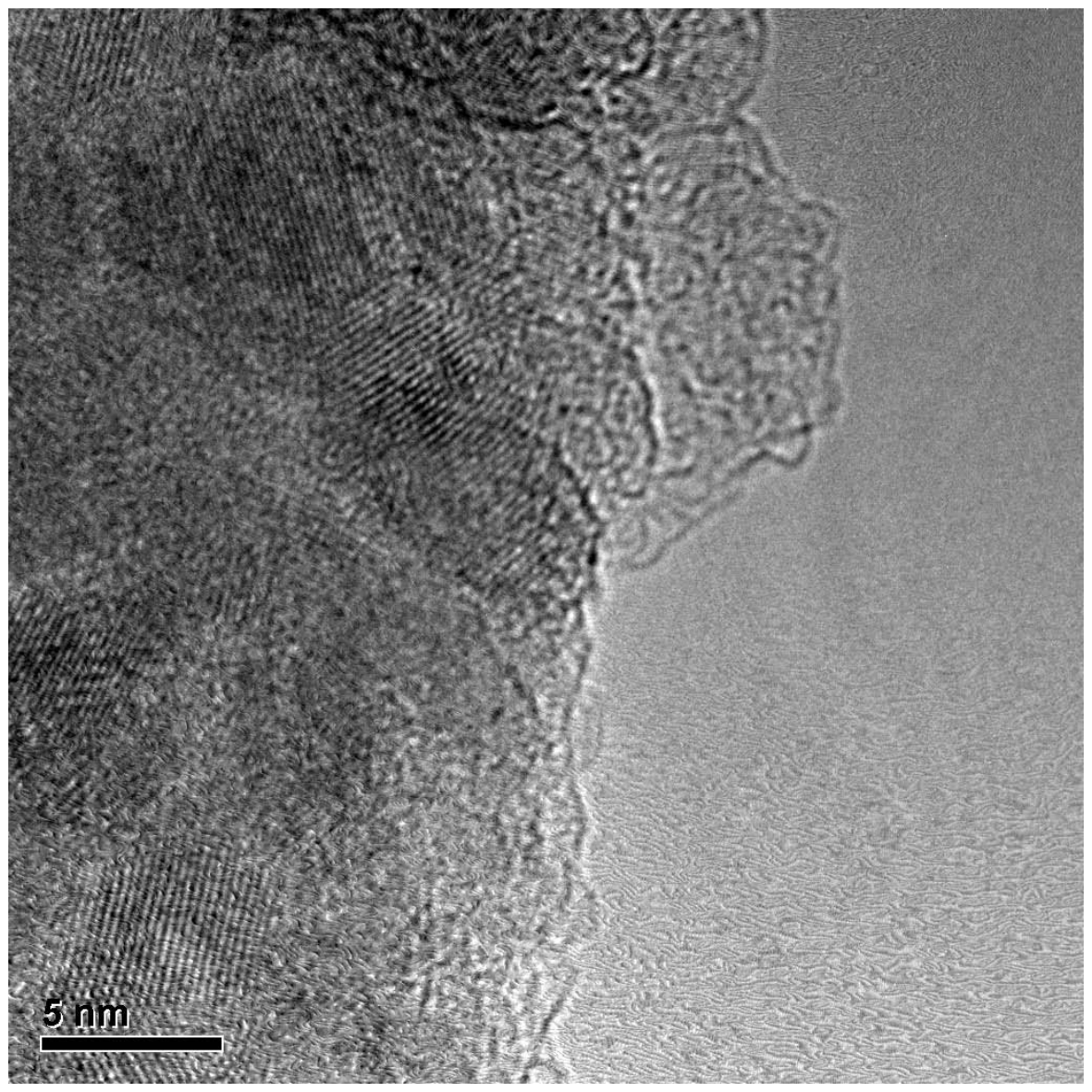

Figure 5: High-resolution TEM image showing lattice fringes within an aggregate of the same type as shown in Figure 1a, i.e. after 5 minutes reaction time. Scale bar $=5 \mathrm{~nm}$. 

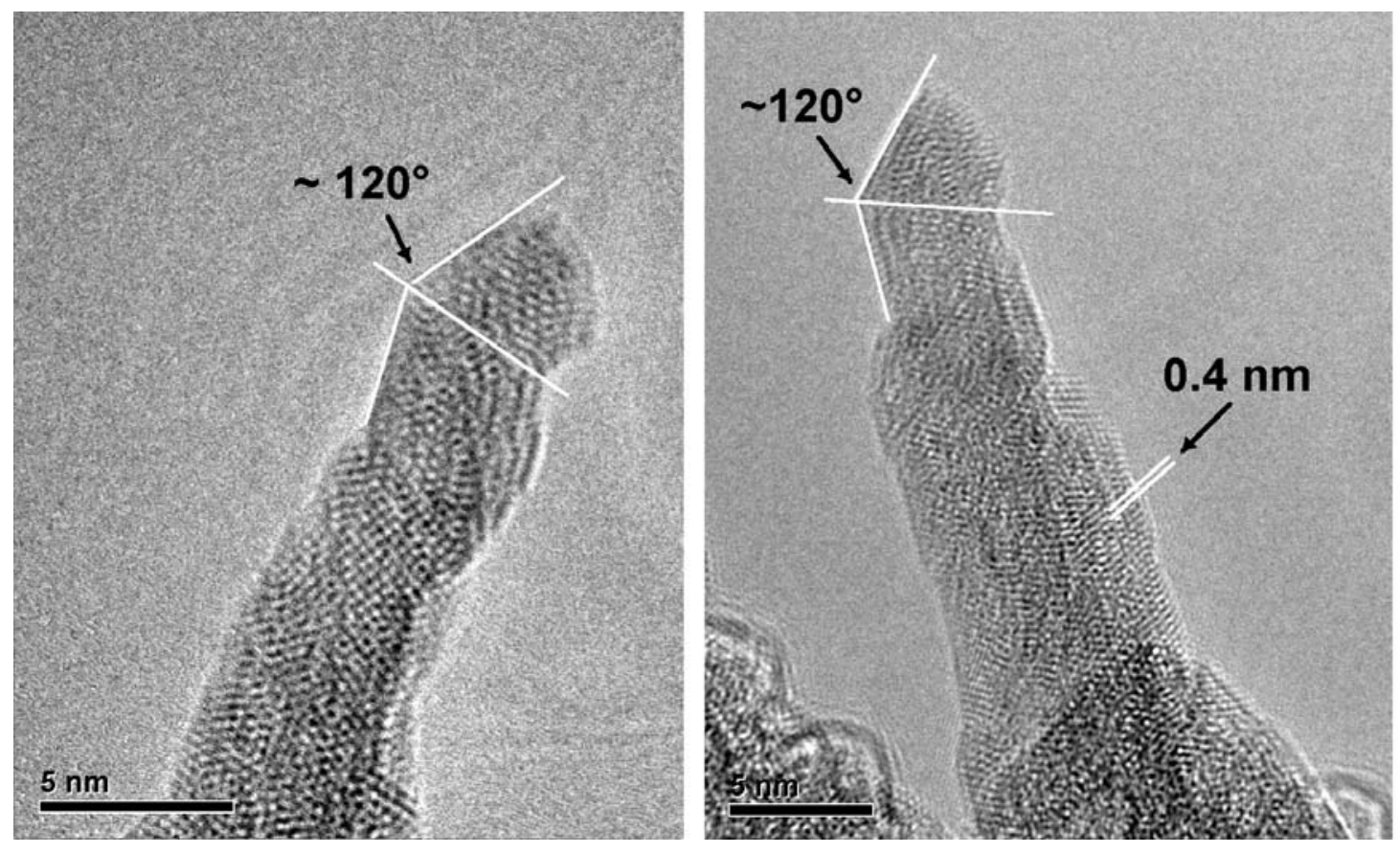

Figure 6: Typical high-resolution TEM images of schwertmannite needles in samples formed after 15 minutes reaction time, showing oriented attachment of goethite nanocrystals at the needle tips, with particles twinned along the (210) plane. Scale bars $=5 \mathrm{~nm}$. 

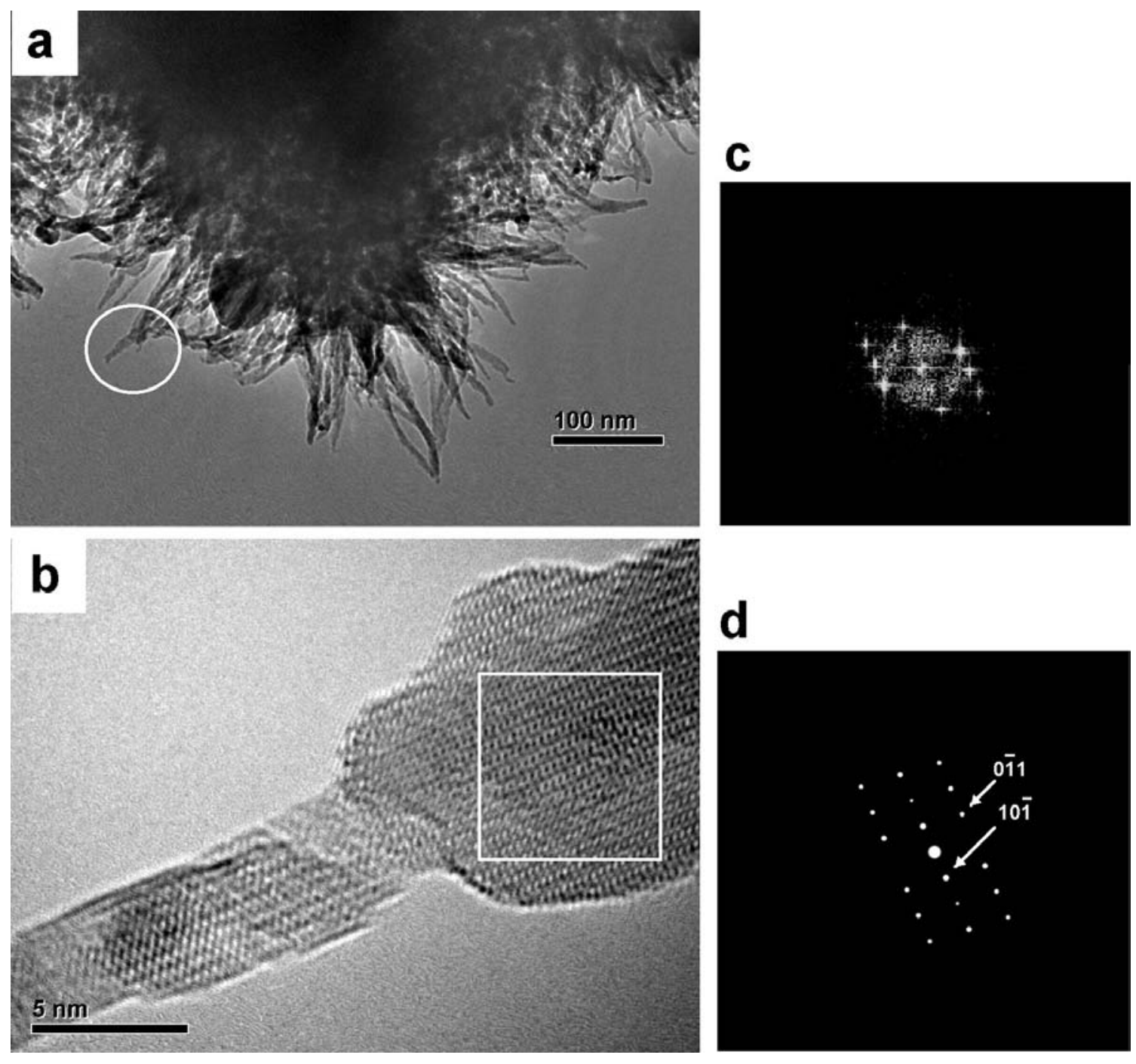

Figure 7: TEM images of a schwertmannite needle after 60 minutes reaction time. a) Low magnification image of a typical schwertmannite aggregate, b) high reslotuion TEM image of the needle circled in a), c) fourier transform of the region shown by the white square in b), d) simulated electron diffraction pattern for goethite viewed along the (111) zone axis. 


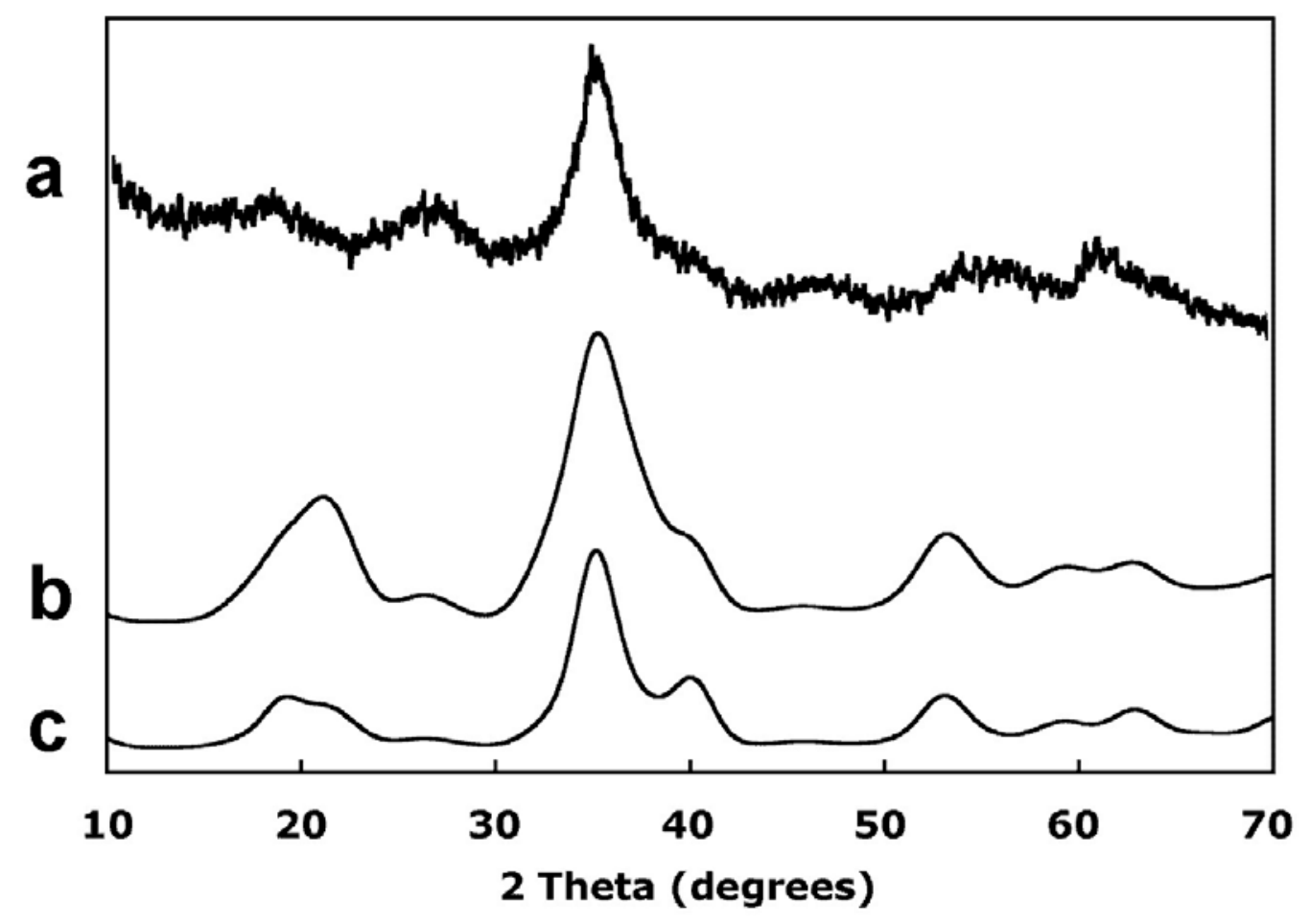

Figure $8:$ a) Powder XRD pattern measured for schwertmannite product collected after 15 minutes reactions time. b) Simulated pattern for a 7:3 mixture of $6 \mathrm{~nm}$ ferrihydrite and $3 \mathrm{~nm}$ goethite nanocrystals. c) Simulated pattern for a 9:1 mixture of $6 \mathrm{~nm}$ ferrihydrite and $3 \mathrm{~nm}$ goethite nanocrystals. 